\title{
Obsessions at Night: Dream Experiences, Emotional Attributes, and Personality Traits as Indicators of Sleep Problems
}

\author{
Calvin Kai-Ching $\mathrm{Yu}^{1^{*}}$ \\ ${ }^{1}$ Department of Counselling and Psychology, Hong Kong Shue Yan University, Hong Kong
}

\begin{abstract}
This study investigated the extent to which negative emotions, personality traits, and obsessive-compulsive distress modulate the relationship between sleep problems and dream experiences. The sample consisted of 610 upper secondary school students, whose subjective intensity of dream experiences, thematic dream content, obsessivecompulsive distress, personality traits, defensiveness, emotional qualities, and sleep disturbances were assessed using the Dream Intensity Scale, Dream Motif Scale, Obsessive-Compulsive Inventory-Revised, NEO Five-Factor Inventory, Marlowe-Crowne Social Desirability Scale, Beck Depression Inventory-II, Beck Anxiety Inventory, State-Trait Anger Expression Iventory-2, and Sleep Habits Questionnaire. The overall findings indicate that waking-life emotionality, personality traits, obsessive-compulsive distress, and other important factors for sleep quality - such as the ability to unwind one's mind when retiring to sleep - moderate but do not mediate the relationship between disrupted sleep and dreaming. It seems, therefore, that dream experiences can serve as unique indicators of sleep problems.
\end{abstract}

Keywords: dream experiences, emotions, obsessive-compulsion, personality, sleep disorders

\section{INTRODUCTION}

Because dreaming forms an integral part of sleep activities, problems that disrupt sleep might inevitably also have impacts on dream experiences. Some attempts have been made to investigate how dream experiences are altered by dyssomnias - such as insomnia, narcolepsy, and sleep-disordered breathing - and parasomnias,

*Correspondence: calvinkcyuaymail.com

Calvin Kai-Ching Yu, Department of Counselling and Psychology, Hong Kong Shue Yan University, 10 Wai Tsui Crescent, Braemar Hill Road, North Point, Hong Kong.

\section{Sleep and Hypnosis \\ Submit your manuscript at www.sleepandhypnosis.org}

including both rapid eye movement (REM) sleep behavior disorder and non-rapid eye movement (NREM) sleep arousal disorders. For instance, research findings indicate that people suffering insomnia (Ohayon, Morselli, \& Guilleminault, 1997; Schredl, 2009a; Schredl, Schäfer, Weber, \& Heuser, 1998), respiratory pauses (de Groen et al., 1993; Schredl, 2008), narcolepsy (Pisko, Pastorek, Buskova, Sonka, \& Nevsimalova, 2014; Schredl, 1998), or REM sleep behavior disorder (RBD) (Fantini, Corona, Clerici, \& Ferini-Strambi, 2005; Uguccioni et al., 2013; Valli et al., 2015) experience more nightmares or bad dreams.

Nonetheless, there are also antithetical findings, which run against the proposition that sleep problems can intensify dream experiences. These include, but are not limited to, the lower dream recall frequency in insomniac patients in comparison with non-insomniac patients 
(Pagel \& Shocknesse, 2007), lower nightmare frequency in patients with sleep-disordered breathing as compared to healthy controls (Schredl \& Schmitt, 2009), nonsignificant differences in the frequencies of unpleasant dreams between low-risk and high-risk groups for sleep apnea (Khazaie, Masoudi, Khoshbakht, \& Ghadami, 2014), and non-significant difference in dream content between RBD patients and healthy controls (D'Agostino et al., 2012). The incompatible findings in relation to the association between sleep problems and dream experiences can be to a certain extent attributed to the diversity and sensitivity of measures adopted by sleep researchers (see Yu \& Thompson, 2016).

Systematically profiling an individual's subjective dream experiences using retrospective scales can constitute a sensitive tool for testing the correlations of dreaming with other variables (Yu, 2007b, 2008, 2010, 2012). Also given the paucity of studies comparing the effects of different sleep problems on dream experiences, Yu and Thompson (2016) administered a checklist of sleep problems (Sleep Habits Questionnaire; Gau, 2000) and validated measures for assessing the thematic content (Dream Motif Scale; Yu, 2012a) and subjective intensities (Dream Intensity Scale; Yu, 2012b) of dreams to secondary school students. They demonstrated that most sleep problems - including those rarely studied by researchers, such as hypersomnia and disrupted circadian rhythm - can intensify various aspects of dreaming, with the effects of sleep paralysis being the most robust and extensive.

Specifically, participants with sleep paralysis experienced more persecutory and sensory dreams such as being tied, unable to move, unable to breath, and killed - than did participants without sleep paralysis. Similarly, compared with other participants, participants suffering sleep-related respiratory pauses were more likely to dream about being smothered and unable to breathe. On the other hand, the dream experiences of sleep bruxists, sleepwalkers, and snorers did not differ significantly from those of participants without the similar problems. Echoing other researchers' findings concerning snoring, apnea, and breathing pauses (de Groen et al. 1993; Gross \& Lavie, 1994; Schredl, 2008), Yu and
Thompson's findings suggest that only sleep problems that draw the sleeper's attention would affect dream experiences.

Waking-life stressors or emotional concerns associated with a sleep problem probably play a critical role in mediating the relationship between sleep problems and dream experiences; that is, such a relationship would not exist if a sleep problem does not cause significant distress. There is abundant evidence that sleep problems can account for or conversely can be explained by various emotional disturbances, including anxiety (e.g., Fite, Becker, Rubens, \& Cheatham-Johnson, 2015; Iwadare et al., 2015; Leblanc, Desjardins, \& Desgagné, 2015; Weiner, Meredith Elkins, Pincus, \& Comer, 2015), depression (e.g., Shittu et al., 2014; Sivertsen, Harvey, Lundervold, \& Hysing, 2014; Zuo, McCabe, Mellor, \& Xu, 2015), and anger or aggression (e.g., Fite et al., 2015; Ireland \& Culpin, 2006; Vaughn, Salas-Wright, White, \& Kremer, 2015). The presence of insomnia or hypersomnia is indeed a diagnostic criterion for mood disorders, including both major depression and bipolar disorders (American Psychiatric Association, 2013). In addition, emerging evidence indicates that sleep problems are highly comorbid with anxiety disorders (see Peterman, Carper, \& Kendall, 2015, for a review) and obsessivecompulsive disorder (see Reynolds, Gradisar, \& Alfano, 2015, for a review).

Obsession is defined as intrusive, persistent thoughts that lead to anxiety and distress (American Psychiatric Association, 2013). The comorbidity between sleep difficulty and obsessive-compulsive disorder can be easily understood when it is considered that ruminative thoughts which prevent the sleeper from relaxing his or her mind and setting aside daytime preoccupations share the persistent feature with obsessive compulsion. Rumination has been found to be not only an important factor for disrupted sleep (Borders, Rothman, \& McAndrew, 2015; Carney, Edinger, Meyer, Lindman, \& Istre, 2006; Guastella \& Moulds, 2007; Querstret \& Cropley, 2012; StoiaCaraballo et al., 2008; Zoccola, Dickerson, \& Lam, 2009) but also a strong correlate of obsessive compulsion (Dar \& Iqbal, 2015; Koch \& Exner, 2015; Wahl, Ertle, Bohne, Zurowski, \& Kordon, 2011; Wahl et al., 2011). 
As with sleep problems, dreaming is sensitive to affect valence and emotional concerns experienced during wakefulness (Gilchrist, Davidson, \& Shakespeare-Finch, 2007; Malinowski, Fylan, \& Horton, 2014; Malinowski \& Horton, 2014; Schredl \& Reinhard, 2009; Yu, 2007a, 2015). According to $Y u(2013 b, 2013 c)$, dream experiences are facilitated by both pleasant and unpleasant emotions - such as anxiety and anger - and suppressed by superego functions, including conscientiousness, agreeableness, and repressive defensiveness. However, the antagonistic relationship between dream experiences and superego functions is rendered non-significant when unpleasant emotions are taken into account. This implies that psychological distress plays a crucial role in mediating the dynamics between superego functioning and dreaming. It is interesting to note, furthermore, that obsessive-compulsive distress and its associated feature - magical ideation - have also been found to positively vary with various dream experiences, such as intense dream episodes, dreaming of themes surrounding the ideal self, and the diffusion of dreamreality memories (Yu, 2013a).

Waking-life distress has been considered a mediator that connects sleep problems and dream experiences, in accordance with the sleep-wake continuity hypothesis (see Schredl, 2009b, 2010). Although the relationship between negative emotions and sleep problems and the relationship between negative emotions and dream experiences are somewhat well documented in the literature, there are surprisingly few, if any, studies demonstrating the extent to which negative emotions modulate the relationship between sleep problems and dream experiences. Yu and Thompson's (2016) study provided a preliminary overview of how specific sleep problems are differentially associated with the phenomenological properties of dreaming. Pursuing this subject matter further, the study presented here was geared toward testing whether dream characteristics are still indicative of sleep problems even with some key factors including negative emotions, personality traits, repressive defensiveness, obsessive-compulsive distress, and magical thinking - being controlled.

\section{METHOD}

\section{Participants}

The sample contained 610 upper secondary school students, 218 (35.7\%) males and 392 (64.3\%) females. The mean age was 19.27 years $(S D=1.067$, range $=18-25)$. Participation was voluntary and without payment.

\section{MATERIALS}

The Dream Intensity Scale (DIS), Dream Motif Scale (DMS), Obsessive-Compulsive Inventory-Revised (OCl-R), Magical Ideation Scale (MIS), NEO Five-Factor Inventory (NEO-FFI), Beck Depression Inventory-II (BDIII), Beck Anxiety Inventory (BAI), State-Trait Anger Expression Iventory-2 (STAXI-2), Marlowe-Crowne Social Desirability Scale (MCSDS), and Sleep Habits Questionnaire (SHQ) were used to assess participants' subjective intensity of dream experiences, thematic dream content, obsessive-compulsive distress, magical thinking, personality traits, emotional qualities, defensiveness, and sleep disturbances, respectively.

DIS. The DIS (Yu, 2010, 2012b) comprises 20 items measuring four primary factors for dream intensity: Dream Quantity, Dream Vividness, Diffusion, and Altered Dream Episodes. The Diffusion scale is composed of the Dream Work and Paramnesia subscales, both of which measure the cognitive distortion that entails the transference of psychical values (e.g., symbolism, displacement). The Paramnesia subscale, for instance, measures the frequency with which people experience the difficulty distinguishing between memories of dreamed and real-life events.

DMS. The DMS ( $Y u, 2012 a)$ evaluates the intrinsic predispositions that modulate the fabrication of dream narratives. It consists of 100 dream themes, various combinations of which can form 14 scales, each measuring a dream predisposition. For example, themes of the Ego Ideal scale are concerned with issues surrounding dreamers' falling short of social expectations and paranoid suspiciousness. The Sensorimotor Excitement Scale is composed of themes involving vigorous bodily movements 


\begin{tabular}{|c|c|c|c|c|c|c|}
\hline \multirow[b]{2}{*}{ Item no. } & \multirow[b]{2}{*}{ DMS themes } & \multicolumn{3}{|c|}{ Classical } & \multicolumn{2}{|c|}{ Logistic } \\
\hline & & $\mathbf{r}$ & $\mathbf{r}^{2}$ & $\alpha$ & Difficulty & Discrimination \\
\hline 4 & Being frozen with fright & .474 & .343 & .785 & -0.382 & 0.845 \\
\hline 8 & Being locked up & .364 & .173 & .797 & 1.426 & 0.963 \\
\hline 15 & Being tied, unable to move & .518 & .363 & .780 & 0.379 & 3.000 \\
\hline 25 & $\begin{array}{l}\text { Vividly sensing (but not necessarily seeing or hearing) } \\
\text { a presence in the room }\end{array}$ & .379 & .194 & .795 & 0.990 & 0.380 \\
\hline 35 & Being smothered, unable to breathe & .525 & .298 & .779 & 0.440 & 1.020 \\
\hline 51 & Being blamed or punished & .545 & .374 & .776 & -2.522 & 0.533 \\
\hline 55 & $\begin{array}{l}\text { Performing a lot of difficult actions to get through } \\
\text { a series of hurdles/obstacles as if you were a stunt man }\end{array}$ & .406 & .189 & .795 & -0.356 & 0.492 \\
\hline 57 & Blaming yourself & .509 & .340 & .781 & -0.177 & 0.751 \\
\hline 61 & Some people are spying on or talking about you & .519 & .354 & .779 & 0.081 & 0.790 \\
\hline 84 & $\begin{array}{l}\text { Feeling dog-tired, lack of strength in the whole body, } \\
\text { and very difficult to move - but you have not } \\
\text { stopped, and keep walking very hard }\end{array}$ & .550 & .319 & .775 & -0.672 & 0.8578 \\
\hline
\end{tabular}

Note. $r=$ Corrected item-total correlation; $r^{2}=$ Squared multiple correlation; $\alpha=$ Cronbach's $\alpha$ if item deleted. The two items with the largest discrimination indices are bolded.

and proprioceptive senses, such as flying, falling, and being chased. In light of the previous evidence that some sleep problems can be signified by dreams involving inhibitions, a new DMS scale was created in the study presented here to measure the monitory and inhibitory propensities in dreams. This new scale contains themes featuring either the physical inhibition of body movements or the psychological prohibition of certain behaviors (see Table 1). As with the original 14 DMS scale, the Inhibition scale is distinguished by its good internal consistency (Cronbach's $\alpha=0.802$ ) and psychometric properties.

OCl-R. The OCl-R (Foa et al., 2002) is an 18-item measure for assessing obsessive-compulsive symptoms. Participants rated the degree to which they were distressed by each obsessive-compulsive experience on a five-point scale. Besides the total score, six subscale scores can be generated from the OCl-R.

MIS. The MIS (Eckblad \& Chapman, 1983), which contains 30 true-false items, is a widely adopted instrument for assessing magical thinking.

NEO-FFI. The NEO-FFI (Costa \& McCrae, 1985) assesses five major personality traits, each with 12 items: neuroticism, extraversion, agreeableness, openness, and conscientiousness.
BDI-II. The BDI-II (Beck, Steer, \& Brown, 1996) is made up of 21 groups of statements. Participants chose one sentence from each group to describe their feeling over the past two weeks. The BDI-II total score ranges from 0 to 63. Higher scores indicate more severe depressive symptoms.

BAI. The BAI (Beck \& Steer, 1990) contains a list of 21 symptoms. Participants rated the severity of each symptom they experienced last week on a four-point scale. The maximum score is 63 , indicating severe anxiety.

STAXI-2. The STAXI-2 (Spielberger, 1999) is a 57-item inventory, which measures both anger as an emotional state (state anger) and the character of perceiving situations as annoying or frustrating (trait anger). Participants rated their feelings, expression, and control of anger on a four-point scale.

MCSDS. Participants' defensiveness was evaluated by the MCSDS (Crowne \& Marlowe, 1960). The current Chinese MCSDS version consists of 32 dichotomous items.

SHQ. The original SHQ (Gau, 2000) comprises 13 brief descriptions similar to the DSM criteria for sleep disorders. Participants indicated whether they had 


\begin{tabular}{|c|c|c|c|c|}
\hline & $\begin{array}{c}\% \\
\text { Lifetime }\end{array}$ & Recent six months & Six months ago & $\mathbf{h}$ \\
\hline \multicolumn{5}{|l|}{ Dyssomnias } \\
\hline Sleep onset insomnia & 23.3 & 14.8 & 14.3 & 0.014 \\
\hline Late insomnia & 12.8 & 8.9 & 8.4 & 0.018 \\
\hline Hypersomnia & 22.5 & 17.0 & 13.9 & 0.086 \\
\hline Sleep paralysis & 22.3 & 9.8 & 20.3 & -0.298 \\
\hline Cataplexy & 3.4 & 2.5 & 2.1 & 0.027 \\
\hline Snoring & 14.1 & 11.8 & 13.3 & -0.045 \\
\hline Sleep-related respiratory pauses & 2.8 & 2.0 & 2.5 & -0.034 \\
\hline Disrupted circadian rhythm & 35.7 & 29.0 & 19.2 & 0.230 \\
\hline \multicolumn{5}{|l|}{ Parasomnias } \\
\hline Recurrent nightmares & 26.1 & 15.4 & 19.8 & -0.116 \\
\hline Sleep terror & 14.4 & 8.5 & 10.8 & -0.078 \\
\hline Sleep bruxism & 15.7 & 8.4 & 14.8 & -0.202 \\
\hline Potential REM sleep behavior (punching and kicking during sleep) & ) 10.2 & 5.4 & 9.5 & -0.158 \\
\hline Restless, jerking, painful legs & 41.8 & 27.2 & 35.4 & -0.177 \\
\hline Sleeptalking & 33.8 & 21.5 & 30.4 & -0.204 \\
\hline Sleepwalking & 4.8 & 0.0 & 4.8 & -0.442 \\
\hline
\end{tabular}

Note. $\mathrm{h}=$ effect size for the difference in the prevalence of a sleep problem between recent six months and six months ago.

experienced each sleep problem over the past six months and six months ago. In the study presented here, the original item "frequent leg movements during sleep" was changed to "frequent leg movements, jerking legs, or leg pain during sleep." Moreover, two new items were added to assess potential REM sleep behavior and hypersomnia: "Frequently and vigorously moving arms and legs, even punching and kicking, during sleep" and "This happens three times a week or more often and lasts for at least one month: Sleeping more than 10 hours at night, being very difficult to wake up from sleep in the morning."

The 15 sleep problems can be categorized into dyssomnias and parasomnias (see Table 2). Excluding the two items for recurrent nightmares, which are similar to some DIS and DMS items, the sum of $28 \mathrm{SHQ}$ item scores gives a total score, which indicates the diversity and chronicity of the sleep problems. The Cronbach's a coefficient for the SHQ global scale was .701. Besides the 15 sleep problems, other data about sleep quality were also collected, such as the number of intermittent awakenings and impacts of sleep disturbances on daytime functioning.

\section{Statistical Strategies}

The correlations of sleep problems with all factors were tested before regression analyses. Factors for regression analyses were selected based on four criteria: 1) the factor or scale was significantly correlated with the sleep problem, 2) the factor or scale showed a larger correlation coefficient than did its similar scales or subscales, 3) the correlation coefficient was larger than one, and 4) the combination of factors or scales being entered into the regression analysis had the least overlap, for example, including either the NEO Neuroticism score or the BDI-II score as an independent variable in a regression analysis.

\section{RESULTS}

Table 2 shows the prevalence rates of dyssomnias and parasomnias. Restless legs, disrupted circadian rhythm, and sleeptalking were the most prevalent sleep problems in the present sample, sleep-related respiratory pauses, cataplexy, and sleepwalking being rare. Disrupted circadian rhythm was more common in the recent six months than six months ago; the reverse was true for sleepwalking, sleep paralysis, sleeptalking, and sleep bruxism. Most (52.5\%) participants slept and rose late; $34.9 \%$ of participants followed a regular sleep schedule. The average duration of sleep was 7.50 (SD= 1.151) hours, which was mildly less than the average of $7.70(S D=1.454)$ hours of sleep that participants 
OCl-R

\begin{tabular}{|c|c|c|c|c|c|c|c|}
\hline & & & & & & & \\
\hline & Total & Hoarding & Checking & Ordering & Neutralizing & Washing & Obsessing \\
\hline \multicolumn{8}{|l|}{ Dyssomnias } \\
\hline Sleep onset insomnia & $0.281^{\star \star *}$ & $0.232^{*}$ & 0.053 & $0.213 * *$ & 0.149 & 0.121 & $0.330^{\star \star *}$ \\
\hline Late insomnia & $0.356^{* *}$ & 0.209 & $0.315^{*}$ & 0.242 & 0.222 & 0.150 & $0.301^{*}$ \\
\hline Hypersomnia & $0.263^{* *}$ & $0.260 * \star$ & 0.060 & $0.244^{*}$ & 0.141 & 0.177 & 0.209 \\
\hline Sleep paralysis & $0.381^{\star \star \star}$ & $0.263^{*}$ & $0.301^{\star *}$ & $0.259 *$ & $0.224^{*}$ & $0.217 *$ & $0.317^{\star \star}$ \\
\hline Cataplexy & 0.453 & $0.497 *$ & 0.115 & 0.178 & 0.328 & $0.444^{*}$ & $0.538^{*}$ \\
\hline Snoring & $0.266^{*}$ & 0.079 & $0.234^{*}$ & $0.228^{*}$ & $0.198^{*}$ & 0.114 & $0.275^{*}$ \\
\hline Sleep-related respiratory pauses & -0.3045 & -0.268 & -0.050 & -0.061 & -0.116 & -0.449 & -0.318 \\
\hline Disrupted circadian rhythm & $0.306^{* \star *}$ & $0.215^{\star *}$ & 0.091 & $0.237 *$ & $0.287^{\star \star *}$ & $0.224^{* *}$ & $0.261^{\star *}$ \\
\hline \multicolumn{8}{|l|}{ Parasomnias } \\
\hline Recurrent nightmares & $0.242^{\star *}$ & 0.157 & $0.275^{\star}$ & 0.100 & 0.106 & 0.132 & $0.235^{\star *}$ \\
\hline Sleep terror & $0.354^{\star \star *}$ & $0.332^{* *}$ & $0.323^{* * *}$ & $0.226^{*}$ & 0.089 & 0.139 & $0.280^{* *}$ \\
\hline Sleep bruxism & 0.061 & 0.026 & 0.144 & 0.052 & -0.045 & -0.010 & 0.060 \\
\hline \multicolumn{8}{|l|}{ Potential REM sleep behavior } \\
\hline (punching and kicking during sleep) & $0.587^{\star * *}$ & $0.503^{* * *}$ & $0.378^{\star *}$ & $0.461^{* \star *}$ & $0.362^{\star *}$ & $0.273^{*}$ & $0.486^{\star * \star}$ \\
\hline Restless, jerking, painful legs & $0.454^{\star * *}$ & $0.369^{* \star *}$ & $0.228^{\star}$ & $0.301^{\star \star *}$ & $0.265^{\star \star}$ & $0.252^{\star \star}$ & $0.422^{\star \star \star *}$ \\
\hline Sleeptalking & 0.135 & 0.135 & 0.018 & 0.117 & -0.023 & 0.082 & $0.204^{\star *}$ \\
\hline Sleepwalking & 0.004 & 0.020 & 0.145 & 0.059 & -0.137 & 0.050 & -0.066 \\
\hline
\end{tabular}

Note. ${ }^{*}=$ Mann-Whitney $\mathrm{U}$ test significant level $<.05,{ }^{* *}=$ Mann-Whitney $\mathrm{U}$ test significant level $<.01,{ }^{* \star *}=$ Mann-Whitney $\mathrm{U}$ test significant level $<.001$.

reckoned as enough $(z=4.059, p<.001$, Cohen's $d=$ -0.152). Most participants, more often than not, could relax their minds when they slept (83.0\%) and felt refreshed after sleep (52.3\%). Almost all participants normally either slept through the night (48.9\%) or had only one or two intermittent awakenings across the night (46.2\%). Around a fifth (18.4\%) of the sample experienced drowsiness and sleep attacks during the day for at least three consecutive months, $15.7 \%$ having trouble concentrating on work or learning for half the time or more often. The habit of daytime napping was reported by $24.9 \%$ of participants.

The SHQ total score exhibited a significant correlation with the DIS global score $\left(r_{s}=.133, p<.01\right)$, but its correlation coefficients with the Bad Dreams $\left(r_{s}=.160, p<\right.$ $.001)$ and Paramnesia subscale scores $\left(r_{s}=.225, p<.001\right)$ were larger. It was also significantly correlated with all 15 DMS scales, with the correlation coefficients for the Inhibition $\left(r_{s}=318, p<.001\right)$ and Ego Ideal $\left(r_{s}=317, p<\right.$ $.001)$ scales being the largest. Its correlations with the three affective attributes were similarly large: BDI-II $\left(r_{s}=\right.$ $.361, p<.001)$, BAI $\left(r_{s}=.393, p<.001\right)$, and STAXI-2 Trait Anger $\left(r_{s}=.336, p<.001\right)$, and STAXI State Anger $\left(r_{s}=\right.$ $.273, p<.001)$. Of the six OCl subscales, the Obsessing subscale had the strongest correlation with the SHQ score $\left(r_{s}=.331, p<.001\right)$. The sex difference for the SHQ total score was not significant $(z=1.494, p>.05$, Cohen's $d=$ 0.143). Although the SHQ score was significantly correlated with both height $\left(r_{s}=.109, p<.01\right)$ and weight $\left(r_{s}=.125, p<.01\right)$, its correlation with the body mass index was negligible $\left(r_{s}=.082, p<.05\right)$.

Participants with potential REM sleep behavior scored significantly higher on all OCl-R subscales than did participants without potential REM sleep behavior (see Table 3). Similar significant between-group differences were noted for the sleep problem of restless legs. Sleep onset insomniacs scored significantly higher on the OCl-R global scale and three of the six OCl-R subscales, with the effect size for the Obsessing subscale being the largest. The effect size for the Obsessing subscale was larger than those for the other subscales in six of the 15 sleep problems. Only three sleep problems did not show a significant difference across all OCl-R scores.

A stepwise regression analysis was conducted for the SHQ total score and a logistic regression analysis was run for each of the 11 specific sleep problems. No regression analysis was performed for cataplexy, sleep bruxism, and 
Table 4: Beta coefficients of the stepwise linear regression model for the total SHQ score and odds ratios (exp(B)) of the forward LR stepwise logistic regression models for distinguishing between participants sustaining specific sleep problem and other participants

\begin{tabular}{|c|c|c|c|c|c|c|c|c|c|c|c|c|}
\hline$\chi^{2}$ & SHQ & $\begin{array}{c}\text { SOl } \\
54.480\end{array}$ & $\begin{array}{c}\text { LI } \\
55.269\end{array}$ & $\begin{array}{c}\text { HS } \\
30.130\end{array}$ & $\begin{array}{c}\text { SP } \\
20.768\end{array}$ & $\begin{array}{c}\text { SN } \\
41.572\end{array}$ & $\begin{array}{c}\text { RP } \\
14.504\end{array}$ & $\begin{array}{c}\text { DCR } \\
76.145\end{array}$ & $\begin{array}{c}\text { NT } \\
37.936\end{array}$ & $\begin{array}{c}\text { PRB } \\
43.778\end{array}$ & $\begin{array}{c}\text { RL } \\
53.205\end{array}$ & $\begin{array}{c}\text { ST } \\
13.931\end{array}$ \\
\hline \multicolumn{13}{|l|}{$\begin{array}{l}\text { DIS } \\
\text { Dream intensity } \\
\text { Dream quantity }\end{array}$} \\
\hline Regular dreams & & & & & & $.945^{\star}$ & & & & & & \\
\hline $\begin{array}{l}\text { Bad dreams } \\
\text { Dream vividness }\end{array}$ & $\mathrm{s}$ & $\mathrm{s}$ & $\mathrm{s}$ & $\mathrm{S}$ & & & & & $\mathrm{s}$ & & & \\
\hline Major modalities & & & & & & & & & & $\mathrm{s}$ & & \\
\hline $\begin{array}{l}\text { Minor modalities } \\
\text { Diffusion }\end{array}$ & & $1.057^{*}$ & & & & & & & & & $\mathrm{~s}$ & \\
\hline Dream work & & & & & & & & & & & & \\
\hline $\begin{array}{l}\text { Paramnesia } \\
\text { Altered dream episodes } \\
\text { Lucid dreaming } \\
\text { Autosuggestion } \\
\text { DMS }\end{array}$ & $\mathrm{s}$ & & & $1.071^{\star}$ & & & & $\mathrm{s}$ & $\mathrm{s}$ & $\mathrm{s}$ & $\mathrm{s}$ & \\
\hline $\begin{array}{l}\text { Inhibition } \\
\text { Delusion }\end{array}$ & $\mathrm{s}$ & $\mathrm{s}$ & $\mathrm{s}$ & $\mathrm{s}$ & $1.051^{*}$ & & $1.088^{*}$ & $\mathrm{~s}$ & $\mathrm{~s}$ & $\mathrm{~s}$ & & \\
\hline $\begin{array}{l}\text { Ego ideal } \\
\text { Grandiosity }\end{array}$ & $\mathrm{s}$ & $\mathrm{s}$ & $\mathrm{s}$ & $\mathrm{s}$ & & & & $1.044^{* * *}$ & $\mathrm{~s}$ & $\mathrm{~s}$ & $\mathrm{~s}$ & $1.018^{*}$ \\
\hline Persecution & & & & & $\mathrm{s}$ & & $\mathrm{s}$ & & $\mathrm{s}$ & & $\mathrm{s}$ & \\
\hline Paranoia & $\mathrm{S}$ & $\mathrm{S}$ & $\mathrm{S}$ & $\mathrm{S}$ & & & & $\mathrm{S}$ & & $1.103 * * *$ & $\mathrm{~s}$ & \\
\hline Erotomania & & & & $\mathrm{s}$ & & & & $\mathrm{s}$ & & $\mathrm{s}$ & & \\
\hline Appetite-instinct & & & & & & & & & & & $\mathrm{s}$ & \\
\hline $\begin{array}{l}\text { Sensorimotor excitement } \\
\text { Sex }\end{array}$ & $.154^{\star \star *}$ & $\begin{array}{l}\mathrm{S} \\
\mathrm{S}\end{array}$ & $1.065^{\star \star}$ & $\mathrm{s}$ & $\mathrm{s}$ & & & $\mathrm{s}$ & $\mathrm{s}$ & $\mathrm{s}$ & $1.044^{\star *}$ & \\
\hline Fighting & & & & & & & & & & $\mathrm{s}$ & $\mathrm{S}$ & \\
\hline Animal symbolism & & & & & & & & $\mathrm{S}$ & & & $\mathrm{s}$ & \\
\hline Unusual creature & & & & & & & & $\mathrm{s}$ & & & & \\
\hline Object relation & & $\mathrm{S}$ & & & & & & $\mathrm{s}$ & & $\mathrm{s}$ & $\mathrm{S}$ & \\
\hline Convenient dreaming & & s & & & & & & $\mathrm{s}$ & & & $\mathrm{s}$ & $\mathrm{s}$ \\
\hline $\begin{array}{l}\text { MCSDS } \\
\text { NEO-FFI } \\
\text { Neuroticism }\end{array}$ & $\mathrm{s}$ & $.946^{*}$ & & $\mathrm{~s}$ & & & & $\mathrm{~s}$ & & $\mathrm{~s}$ & $\mathrm{~s}$ & \\
\hline Extraversion & & $\mathrm{s}$ & & & & & & & & & & \\
\hline Openness & & & & & & & & $1.049 *$ & & & & \\
\hline Agreeableness & $\mathrm{S}$ & $\mathrm{S}$ & & $\mathrm{S}$ & & & & $\mathrm{s}$ & & & & \\
\hline Conscientiousness & $\mathrm{s}$ & & & $\mathrm{s}$ & & & & s & & & & \\
\hline BDI-II & $\mathrm{s}$ & $\mathrm{s}$ & $\mathrm{S}$ & $\mathrm{s}$ & & & & $1.048^{*}$ & $\mathrm{~s}$ & $\mathrm{~s}$ & $\mathrm{~s}$ & \\
\hline $\begin{array}{l}\text { BAI } \\
\text { STAXI-2 }\end{array}$ & $.154^{\star \star \star}$ & $1.043^{*}$ & $\mathrm{~s}$ & $\mathrm{~s}$ & $\mathrm{~s}$ & & & $\mathrm{~s}$ & $1.065^{\star *}$ & $1.087^{\star * *}$ & $1.072^{\star * *}$ & $\mathrm{~s}$ \\
\hline State Anger & $\mathrm{S}$ & $\mathrm{S}$ & & $\mathrm{S}$ & & & & $\mathrm{S}$ & $\mathrm{s}$ & $\mathrm{s}$ & $\mathrm{s}$ & \\
\hline $\begin{array}{l}\text { Trait Anger } \\
\text { OCl-R }\end{array}$ & $\mathrm{s}$ & $\mathrm{s}$ & & & $\mathrm{s}$ & & & $\mathrm{s}$ & $\mathrm{s}$ & & $\mathrm{s}$ & \\
\hline OCl-R total & $.096 *$ & & $\mathrm{~s}$ & $\mathrm{~s}$ & $1.032 *$ & & & & $\mathrm{~s}$ & $\mathrm{~s}$ & $1.029 *$ & \\
\hline $\begin{array}{l}\text { Hoarding } \\
\text { Checking }\end{array}$ & & & & & & & & $\mathrm{s}$ & & & & \\
\hline Ordering & & $\mathrm{s}$ & & & & & & & & & & \\
\hline Neutralizing & & & & & & & & $\mathrm{S}$ & & & & \\
\hline Washing & & & & & & & & $\mathrm{s}$ & & & & \\
\hline Obsessing & & $\mathrm{s}$ & & & & & & $\mathrm{s}$ & & & & $\mathrm{s}$ \\
\hline MIS & $.115^{\star \star}$ & $\mathrm{s}$ & $\mathrm{s}$ & $1.071^{\star \star}$ & $\mathrm{s}$ & & & $\mathrm{s}$ & $1.064^{\star}$ & & $\mathrm{s}$ & \\
\hline Other factors & & & & & & & & & & & & \\
\hline Gender & & & & & & $\mathrm{S}$ & & & & & & \\
\hline Height & $\mathrm{s}$ & & & & & $\mathrm{s}$ & & $\mathrm{s}$ & & s & & \\
\hline Weight & $.135^{\star \star *}$ & & & & & $1.024 * * \star$ & & $1.016^{* * *}$ & & $1.017^{\star \star}$ & & \\
\hline Body Mass Index & & & & & & $\mathrm{s}$ & & $\mathrm{s}$ & & & & \\
\hline $\begin{array}{l}\text { Being able to relax your } \\
\text { mind or not when sleeping } \\
\text { Number of intermittent }\end{array}$ & $-.157^{\star \star \star}$ & $.637 * \star$ & $.533^{\star \star *}$ & $.651^{\star \star}$ & & & $.562^{\star}$ & & & & & \\
\hline awakenings during sleep & $.136^{\star \star \star}$ & $1.394^{*}$ & $2.403 * * *$ & & & & $1.844^{*}$ & & $1.525^{\star}$ & & & $1.409 *$ \\
\hline Drinking coffee & $\mathrm{s}$ & & & & & & & $1.409 * *$ & & & & \\
\hline Drinking alcohol & $.111^{\star \star}$ & & & & & $4.704^{\star \star}$ & & $\mathrm{s}$ & $4.359 * *$ & & & \\
\hline
\end{tabular}

Note. $\mathrm{SHQ}=\mathrm{SHQ}$ global score; $\mathrm{SOI}=$ sleep onset insomnia; $\mathrm{LI}=$ late insomnia; $\mathrm{HS}=$ hypersomnia; $\mathrm{SP}=$ sleep paralysis; $\mathrm{SN}=$ snoring; $\mathrm{RP}=$ respiratory pauses; $\mathrm{DCR}=$ disrupted circadian rhythm; $\mathrm{NT}=$ night terror; $\mathrm{PRB}=$ potential REM sleep behavior; $\mathrm{RL}=$ restless legs; $\mathrm{ST}=$ sleeptalking. The $\mathrm{p}$ value for all logistic regression models was $<.001$, except that for the RP model $(p=.002)$. $\mathrm{s}=$ significant correlate that was entered into but was eliminated by the regression analysis. ${ }^{*}=\mathrm{t}$-test significant level/ Wald test significant level $<.05,{ }^{* *}=\mathrm{t}$-test significant level/ Wald test significant level $<.01,{ }^{* \star *}=\mathrm{t}$-test significant level/ Wald test significant level $<.001$. 
sleepwalking because none of their correlation coefficients with dream or sleep factors were larger than one. Likewise, since the problem of recurrent nightmares by itself is a dream experience and overlaps with some DIS and DMS items, no regression model was generated for this sleep problem.

The resultant regression models are presented in Table 4. Only the model for night terror did not consist of a dream factor. One of the factors included in this model was the number of intermittent awakenings, which can be considered a clinical feature of night terror. The reanalysis of night terror by excluding the number of intermittent awakenings resulted in a three-factor model $(x 2=33.189$, $\mathrm{p}<.001$ ) made up of the Bad Dreams subscale (Wald= 5.175, $\operatorname{Exp}(B)=1.093, p<.05)$, the BAI (Wald $=15.235$, $\operatorname{Exp}(B)=1.077, p<.001)$, and the habit of drinking alcohol $(W a l d=7.464, \operatorname{Exp}(B)=4.323, p<.01)$. In a similar vein, the model for late insomnia was replicated even without the number of intermittent awakenings being entered into the regression analysis $(X 2=33.927, p<.001)$; the Sensorimotor Excitement scale (Wald $=10.294, \operatorname{Exp}(B)=$ $1.063, p<.01)$ and the inability to unwind one's mind during sleep $(\mathrm{Wald}=19.598, \operatorname{Exp}(B)=.482, \mathrm{p}<.001)$ were retained in the model.

Among the eight predictors of the regression model for the SHQ total score $(F=25.336, p<.001, R 2=.283)$, the inability to unwind one's mind was the strongest, followed by the Sensorimotor Excitement scale and the BAI. These three factors, together with the number of intermittent awakenings during sleep, constituted some common factors for the sleep problems. The inability to unwind one's mind was a positive predictor in most dyssomnia models. The BAI was a significant correlate of all sleep problems except snoring and respiratory pauses and was a significant predictor in five regression models. The Inhibition scale positively predicted sleep paralysis and respiratory pauses, the Sensorimotor Excitement scale being indicative of the SHQ total score, late insomnia, and restless legs. Snoring was the only sleep problem that was negatively related to dream factors, especially the Regular Dreams subscale. The OCI-R total score positively predicted the SHQ total score, sleep paralysis, and restless legs.

\section{DISCUSSION}

Yu and Thompson (2016) demonstrated that each sleep problem has a distinct pattern of associations with the phenomenological properties of dreaming. Nevertheless, waking-life emotionality, to which both sleep problems and dream experiences are sensitive, might decisively mediate the relationship. Therefore, the study presented here examined the relationship between sleep problems and dream experiences with consideration of negative emotions, obsessive-compulsive distress, and other potential mediators. In addition to the DIS, DMS,

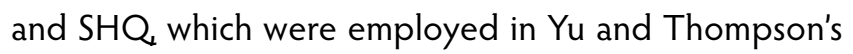
study, standard questionnaires, such as NEO-FFI, BDI-II, and $\mathrm{BAl}$, were administered to participants in a bid to comprehensively assess their personality traits, emotional attributes, and obsessive-compulsive distress.

As expected, the SHQ total score and most individual sleep problems exhibited robust associations with negative emotions and obsessive-compulsive distress, with the effects of anxiety and obsessive symptoms being strongest. Overall, dream variables significantly predicted the SHQ total score and almost all sleep problems, even after controlling all significant correlates. This suggests that waking-life emotionality, personality traits, obsessivecompulsive distress, and other important factors for poor sleep quality - such as body mass index, caffeine and alcohol intake, night waking, and the inability to relax one's mind when retiring to sleep - moderate rather than mediate the connection between disrupted sleep and dreaming.

The phenomenological factors of dreaming therefore seem to serve as unique indicators of sleep problems. In particular, circadian rhythm sufferers and sleeptalkers might be more likely to dream about performance anxiety or falling short of social expectations. Likewise, dreaming of inhibitory themes might be derived from sleep paralysis and respiratory pauses; vigorous movements and sensations in dreams might be seen to correspond to leg restlessness and pain during sleep. Also considering that the inability to unwind one's mind while sleeping, anxiety symptoms, and obsessive thoughts are common, robust factors for sleep problems, tactics aimed at 
dissociating oneself from the hustle and bustle of the waking life while lying on the bed, managing obsessive preoccupations, and working through issues revealed by dreams probably constitutes an effective therapy for sleep difficulty.

The findings of the current study largely resonate with those of Yu and Thompson's (2016) study. In both studies, restless legs, disrupted circadian rhythm, and sleeptalking were the most prevalent sleep problems, whereas respiratory pauses, cataplexy, and sleepwalking were the rarest. In both studies, sleepwalking, sleeptalking, and sleep bruxism occurred far more commonly in earlier life. In both studies, furthermore, participants, who suffered sleep paralysis or respiratory pauses, more often experienced inhibitory forces in dreams. However, there were also some inconsistent findings. For instance, $\mathrm{Yu}$ and Thompson found that snorers and non-snorers did not differ in any dream variables, whereas the dream experiences of non-snorers were significantly stronger

\section{References}

American Psychiatric Association (2013). Diagnostic and statistical manual of mental disorders ( $5^{\text {th }}$ ed.). Arlington, VA: American Psychiatric Association.

Beck, A. T, Steer, R. A. (1990). Manual for the Beck Anxiety Inventory. San Antonio, TX: Psychological Corporation.

Beck, A. T., Steer, R. A., \& Brown, G. K. (1996). Manual for the Beck Depression Inventory-II. San Antonio, TX: Psychological Corporation.

Borders, A., Rothman, D. J., \& McAndrew, L. M. (2015). Sleep problems may mediate associations between rumination and PTSD and depressive symptoms among OIF/OEF veterans. Psychological Trauma: Theory, Research, Practice, and Policy, 7(1), 76-84.

Carney, C. E., Edinger, J. D., Meyer, B., Lindman, L., \& Istre, T. (2006). Symptom-focused rumination and sleep disturbance. Behavioral Sleep Medicine 4(4), 228-241.

Costa, P. T. Jr., McCrae, R. R. (1985). The NEO Five-Factor Inventory. U.S.A.: Psychological Assessment Resources, Inc.

Crowne DP, Marlowe D. (1964). The approval motive. New York: Wiley.

D'Agostino A, Manni R, Limosani I, Terzaghi M, Cavallotti S, \& Scarone S. (2012). Challenging the myth of REM sleep behavior disorder: No evidence of heightened aggressiveness in dreams. Sleep Medicine, 13(6), 714-719.

Dar, K. A., Iqbal, N. (2015). Worry and rumination in generalized anxiety disorder and obsessive compulsive disorder. Journal of Psychology, 149(8): 866-880.

de Groen, J. H., Op den Velde, W., Hovens, J. E., Falger, P. R., Schouten, E. G., \& van Duijn, H. (1993). Snoring and anxiety dreams. Sleep 16(1), 35-36. than those of snorers in the study presented here. Similarly, Yu and Thompson's finding that sleeptalkers experienced more autosuggestive episodes than did the non-sleeptalkers was not replicated in the current study.

The dissimilar findings can be at least partially ascribed to the different characteristics of the two samples. The present sample ( $M=19.27$ years old) was made up of participants who had already completed all public examinations for university entry, while Yu and Thompson's previous sample ( $M=17.75$ years old $)$ consisted of younger participants who were preparing for the examinations. As reflected by the longer duration of sleep ( 7.50 hours vs. 6.31 hours) and the lower prevalence of daytime drowsiness ( $18.4 \%$ vs. $35.9 \%)$, the sleep quality of participants in the present sample seemed to be better than that of participants in Yu and Thompson's sample. The role of developmental factors or crises in the relationship between sleep difficulty and dreaming, however, requires clarification through further investigation.

Eckblad, M., Chapman, L. J. (1983). Magical ideation as an indicator of schizotypy. Journal of Consulting and Clinical Psychology, 51(2), 215-225.

Fantini, M. L., Corona, A., Clerici, S., \& Ferini-Strambi, L. (2005). Aggressive dream content without daytime aggressiveness in REM sleep behavior disorder. Neurology 65(7), 1010-1015.

Fite, P. J., Becker, S. P., Rubens, S. L., \& Cheatham-Johnson, R. (2015). Anxiety symptoms account for the link between reactive aggression and sleep problems among Latino adolescents. Child and Youth Care Forum 44(3). 343-354.

Foa, E. B., Huppert, J. D., Leiberg, S., Langner, R., Kichic, R., Hajcak, G., \& Salkovskis, P. M. (2002). The Obsessive-Complusive Inventory: Development and validation of a short version. Psychological Assessment, 14(4), 485-495.

Gau, S. F. (2000). Neuroticism and sleep-related problems in adolescence. Sleep, 23(4), 495-502.

Gilchrist, S., Davidson, J., \& Shakespeare-Finch, J. (2007). Dream emotions, waking emotions, personality characteristics and wellbeing - A positive psychology approach. Dreaming, 17(3), 172185.

Gross, M., Lavie, P. (1994). Dreams in sleep apnea patients. Dreaming, 4(3), 195-204.

Guastella, A. J, Moulds, M. L. (2007). The impact of rumination on sleep quality following a stressful life event. Personality and Individual Differences, 42(6), 1151-1162.

Ireland, J. L., Culpin, V. The relationship between sleeping problems and aggression, anger, and impulsivity in a population of juvenile and young offenders. Journal of Adolescent Health, 38(6), 649-655. 
Iwadare, Y., Kamei, Y., Usami, M., Ushijima, H., Tanaka, T., Watanabe, K., Kodaira, M., \& Saito, K. (2015). Behavioral symptoms and sleep problems in children with anxiety disorder. Pediatrics International, 57(3), 690-693.

Khazaie, H., Masoudi, M., Khoshbakht, S., \& Ghadami, M. R. Unpleasant dream content and risk of sleep apnea. African Journal of Psychiatry, 17(5), 1-4.

Koch, J., Exner, C. (2015). Selective attention deficits in obsessivecompulsive disorder: The role of metacognitive processes. Psychiatry Research, 225(3), 550-555.

Leblanc, M. F., Desjardins, S., \& Desgagné, A. (2015). Sleep problems in anxious and depressive older adults. Psychology Research and Behavior Management, 8, 161-169.

Malinowski, J., Fylan, F., \& Horton, C. L. (2014). Experiencing 'continuity': A qualitative investigation of waking life in dreams. Dreaming, 24(3), 161-175.

Malinowski, J., Horton, C. L. (2014). Evidence for the preferential incorporation of emotional waking-life experiences into dreams. Dreaming, 24(1), 18-31.

Ohayon, M. M., Morselli, P. L., \& Guilleminault, C. (1997). Prevalence of nightmares and their relationship to psychopathology and daytime functioning in insomnia subjects. Sleep, 20(5), 340-348.

Pagel, J. F, Shocknesse, S. (2007). Dreaming and insomnia: Polysomnographic correlates of reported dream recall frequency. Dreaming, 17(3), 140-151.

Peterman, J. S., Carper, M. M., \& Kendall, P. C. (2015). Anxiety disorders and comorbid sleep problems in school-aged youth: Review and future research directions. Child Psychiatry and Human Development, 46(3), 376-392.

Pisko, J., Pastorek, L., Buskova, J., Sonka, K., \& Nevsimalova, S. (2014). Nightmares in narcolepsy: Underinvestigated symptom? Sleep Medicine 15(8), 967-972.

Querstret, D., Cropley, M. (2012). Exploring the relationship between work-related rumination, sleep quality, and work-related fatigue. Journal of Occupational Health Psychology, 17(3), 341353.

Reynolds, K. C., Gradisar, M., \& Alfano, C. A. (2015). Sleep in children and adolescents with obsessive-compulsive disorder. Sleep Medicine Clinics, 10(2), 133-141.

Schredl M. (2009a) Nightmare frequency in patients with primary insomnia. International Journal of Dream Research, 2(2), 85-88.

Schredl, M. (2008). Snoring, breathing pauses, and nightmares. Perceptual and Motor Skills, 106(3), 690-692

Schredl, M. (2009b). Dreams in patients with sleep disorders. Sleep Medicine Reviews, 13(3), 215-221.

Schredl, M. (2010). Do sleep disorders affect the dreaming process? Dream recall and dream content in patients with sleep disorders. Sleep Medicine Clinics, 5(2), 193-202.

Schredl, M., Reinhard, I. (2009). The continuity between waking mood and dream emotions: Direct and second-order effects. Imagination, Cognition and Personality, 29(3), 271-282.

Schredl, M., Schäfer, G., Weber, B., \& Heuser, I. (1998). Dreaming and insomnia: Dream recall and dream content of patients with insomnia. Journal of Sleep Research, 7(3), 191-198.

Schredl, M., Schmitt, J. (2009). Traumerinnerungshäufigkeit und Alptraumhäufigkeit bei Patienten mit nächtlichen Atemregulationsstörungen (Dream recall frequency and nightmare frequency in patients with sleep-disordered breathing). Somnologie, 13(1), 12-17.
Shittu, R. O., Sanni, M. A., Odeigah, L. O., Baba, I. A., Olanrewaju, G. T., Sule, A. G., \& Isiaka-Lawal, S. (2014). Depression and sleep problems in a Nigerian family practice setting. International Journal of Dream Research, 7(2), 113-120.

Sivertsen, B., Harvey, A., Lundervold, A., \& Hysing, M. (2014). Sleep problems and depression in adolescence: Results from a large population-based study of Norwegian adolescents aged 16-18 years. European Child and Adolescent Psychiatry, 23(8), 681-689.

Spielberger, C. D. (1999). Manual for the State-Trait Anger Expression Inventory-2. Odessa, FL: Psychological Assessment Resources.

Stoia-Caraballo, R., Rye, M. S., Pan, W., Kirschman, K., Lutz-Zois, C., \& Lyons, A. M. (2008). Negative affect and anger rumination as mediators between forgiveness and sleep quality. Journal of Behavioral Medicine, 31(6), 478-488.

Uguccioni, G., Golmard, J. L., de Fontréaux, A. N., Leu-Semenescu, S., Brion, A. \& Arnulf, I. (2013). Fight or flight? Dream content during sleepwalking/sleep terrors vs rapid eye movement sleep behavior disorder. Sleep Medicine, 14(5), 391-398.

Valli, K., Frauscher, B., Peltomaa, T., Gschliesser, V., Revonsuo, A., \& Högl, B. (2015). Dreaming furiously? A sleep laboratory study on the dream content of people with Parkinson's disease and with or without rapid eye movement sleep behavior disorder. Sleep Medicine, 16(3), 419-427.

Vaughn, M. G., Salas-Wright, C. P. White, N. A., \& Kremer, K. P. (2015). Poor sleep and reactive aggression: Results from a national sample of African American adults. Journal of Psychiatric Research, 6667, 54-59.

Wahl, K., Ertle, A., Bohne, A., Zurowski, B., \& Kordon, A. (2011). Relations between a ruminative thinking style and obsessivecompulsive symptoms in non-clinical samples. Anxiety, Stress and Coping, 24(2), 217-225.

Wahl, K., Schönfeld, S., Hissbach, J., Küsel, S., Zurowski, B., Moritz, S., Hohagen, F., \& Kordon, A. (2011). Differences and similarities between obsessive and ruminative thoughts in obsessivecompulsive and depressed patients: A comparative study. Journal of Behavior Therapy and Experimental Psychiatry, 42(4), 454-461.

Weiner, C. L., Meredith Elkins, R. , Pincus, D., \& Comer, J. (2015). Anxiety sensitivity and sleep-related problems in anxious youth. Journal of Anxiety Disorders, 32, 66-72.

Yu, C. K. C. (2007a). Emotions before, during, and after dreaming sleep. Dreaming, 17(2), 73-86.

Yu, C. K. C. (2007b). Dream recall and the dissociation between dream cessation and neurological memory disorders. NeuroPsychoanalysis, 9(2), 213-221.

Yu, C. K. C. (2008). Dream Intensity Inventory and Chinese people's dream experience frequencies. Dreaming, 18(2), 94-111.

Yu, C. K. C. (2010). Dream Intensity Scale: Factors in the phenomenological analysis of dreams. Dreaming, 20(2), 107-129.

Yu, C. K. C. (2012a). Dream Motif Scale. Dreaming, 22(1), 18-52.

Yu, C. K. C. (2012b). Testing the factorial structure of the Dream Intensity Scale. Dreaming; 22(4), 284-309.

Yu, C. K. C. (2013a). Obsessive-compulsive distress and its dynamic associations with schizotypy, borderline personality, and dreaming. Dreaming, 23(1), 46-63.

Yu, C. K. C. (2013b). The structural relations between the superego, instinctual affect, and dreams. Dreaming, 23(2), 145-155.

Yu, C. K. C. (2013c). Superego and the repression of affective and dream experiences. Dreaming, 23(4), 266-276. 
Yu, C. K. C. (2015). The vicissitudes of affective valence across the night: A high-density electroencephalographic study. Dreaming, 25(4), 274-290.

Yu, C. K. C., Thompson, N. S. (2016). Sleep problems and the phenomenological factors of dreaming. Sleep and Hypnosis, 18(1), 8-18.
Zoccola, P. M., Dickerson S. S., \& Lam S. (2009). Rumination predicts longer sleep onset latency after an acute psychosocial stressor. Psychosomatic Medicine, 71(7), 771-775.

Zuo, S., McCabe, M. P., Mellor, D., \& Xu, Y. (2015). Sleep problems among clinically depressed adults in China. Journal of Mental Health, 24(1), 43-47. 